\title{
Do Protocolo aos Desafios Cotidianos: a Experiência Profissional de Bombeiros Militares
}

\author{
Cristiano Dal Forno ${ }^{1}$ \\ Mônica Medeiros Kother Macedo ${ }^{2}$ \\ ${ }^{1}$ Pontifícia Universidade Católica do Rio Grande do \\ Sul, RS, Brasil. \\ ${ }^{2}$ Universidade Federal do Rio Grande do Sul, RS, Brasil.
}

Resumo: Dentre as diversas profissões existentes, algumas se dedicam ao ofício de cuidar, o que implica, muitas vezes, em um investimento de energia e interesse particularmente voltado à necessidade e à demanda do outro. Este artigo retrata um estudo sobre bombeiros militares que se dedicou a compreender a vivência singular do exercício laboral de assistência e cuidado desses profissionais. Entrevistaram-se três bombeiros militares e os dados obtidos foram analisados qualitativamente por meio da Análise de Conteúdo, do que resultaram três categorias finais: "A permanente e incondicional disponibilidade ao outro como marca identitária"; "Os tensionamentos entre o protocolo e o cotidiano"; e "Retaguarda institucional ao sujeito que salva: nuances do reconhecimento externo e do amparo ao cuidador". A interpretação dos achados se deu por meio de aportes da Psicanálise e da Psicodinâmica do Trabalho. Resulta que quem salva e cuida é o sujeito, na medida em que é ele que realiza o trabalho, construindo soluções criativas para além das prescrições do protocolo.

Palavras-chave: Trabalho, Psicanálise, Psicodinâmica do Trabalho, Identidade, Bombeiros.

\section{From Protocol to Daily Challenges: The Military Firefighter's Professional Experience}

\begin{abstract}
Among the variety of existing professions, some are devoted to caring, which implies, many times, an investment of energy and interest particularly directed to the other's necessity and demand. This article outlines a study on military firefighters aimed at understanding the unique work of these professionals in terms of providing care and assistance. Three military firefighters were interviewed and data obtained were qualitatively analyzed by Content Analysis, resulting in three final categories: "Sustained and unconditional availability to others as an identity marker"; "Tensions between protocol and everyday life"; and "Institutional safeguarding of subjects who save: nuances of external recognition and support for caregivers”. The findings were interpreted through Psychoanalysis and Work Psychodynamics contributions. The result is that individuals who save and protect are subjects insofar as they carry out the work, constructing creative solutions that go beyond the requirements of the protocol.
\end{abstract}

Keywords: Work, Psychoanalysis, Work Psychodynamics, Identity, Firefighters. 


\title{
Del Protocolo a los Desafíos Cotidianos: la Experiencia Profesional de Bomberos Militares
}

\begin{abstract}
Resumen: Dentro de las diversas profesiones que existen, algunas se dedican al oficio de cuidar, lo que implica muchas veces una inversión de energía e intereses particularmente dirigidos a la necesidad y a la demanda del otro. Este artículo refleja un estudio sobre los bomberos militares que se dedicaron a comprender la vivencia particular del ejercicio laboral de la asistencia y el cuidado de estos profesionales. Se entrevistaron tres bomberos militares y los datos obtenidos fueron analizados cualitativamente por medio del Análisis de Contenido, del que surgieron tres categorías finales: "La permanente e incondicional disponibilidad al otro como marca de identidad", "las tensiones entre el protocolo y lo cotidiano", y "La retaguardia institucional para el sujeto que salva: matices del reconocimiento externo y del amparo al cuidador". La interpretación de los resultados se hizo por medio de los aportes del Psicoanálisis y de la Psicodinámica del trabajo. Resulta que quien salve y cuida es el sujeto, en la medida que es él que realiza el trabajo, construyendo soluciones creativas más allá de las prescripciones del protocolo.
\end{abstract}

Palabras clave: Trabajo, Psicoanálisis, Psicodinámica del Trabajo, Identidad, Bomberos.

\section{Introdução}

Dentre as diversas profissões, algumas dedicam seu ofício à necessidade e à demanda do outro. De maneira particular, os bombeiros constituem uma classe de profissionais cuidadores que, quando chamada, tem na efetividade e no sucesso de sua ação a manutenção de vidas humanas que, de outro modo, possivelmente seriam perdidas. A missão principal do Corpo de Bombeiros é a preservação da vida, do meio ambiente e do patrimônio, não estando excluídas de suas atribuições atividades de preservação da ordem pública, visto que pertencem à Polícia Militar. A atuação primordial desse órgão militar dá-se por meio da execução de atividades de defesa civil, tais como prevenção e extinção de incêndios, proteção e salvamento de vidas humanas, socorro a afogamentos, inundações, desabamentos, acidentes, calamidades públicas e catástrofes (Gonzales, Donaduzzi, Beck, \& Stekel, 2006).

$\mathrm{O}$ recente episódio da Boate Kiss, que vitimou fatalmente 242 pessoas e deixou muitas mais feridas, em acidente ocorrido no início de 2013 no interior do Rio Grande do Sul, pôs em evidência o trabalho de profissionais em situações trágicas. Dentre esses, destacaram-se os bombeiros militares, cuja atuação repercutiu de forma significativa, sendo suas condições profissionais e pessoais postas à prova, suscitando alternância entre o reconhecimento do valor de suas ações e o questionamento acerca de seus efetivos recursos de intervenção em situações catastróficas. Em vista disso, buscou-se o acesso a esses profissionais a fim de conhecer suas narrativas a respeito de uma rotina na qual a prontidão é imprescindível. A relevância deste estudo situa-se, desse modo, em sua perspectiva de lançar luz sobre a complexidade de um labor profissional cercado de complexas demandas sociais.

A compreensão aprofundada das experiências de uma prática profissional somente pode ser buscada por meio de uma escuta particularizada e atenta às nuances subjetivas. Assim, o presente artigo retrata uma pesquisa que se dedicou a compreender a vivência singular do exercício laboral de assistência e cuidado, a partir do relato de profissionais bombeiros. Para tanto, foram realizadas entrevistas com bombeiros gaúchos pertencentes a quartéis tanto da capital quanto de cidades do interior do Estado. A Psicanálise e a Psicodinâmica do Trabalho foram assumidas como campos teóricos nos quais se buscaram os fundamentos para problematizar a experiência e a vivência desses profissionais.

\section{Método}

\section{Participantes}

Participaram do estudo três bombeiros militares, do sexo masculino, pertencentes a diferentes 
Comandos de Bombeiros do Estado do Rio Grande do Sul/Brasil, com experiência profissional de, pelo menos, cinco anos na corporação, em função operacional. A escolha dos participantes foi aleatória em um grupo de cerca de 30 profissionais que, na ocasião da pesquisa, encontravam-se em formação na capital, garantindo-se o anonimato dos mesmos pela atribuição de pseudônimos, inspirados nos heróis da mitologia grega. Ainda que a questão inicial tenha surgido relacionada à ocorrência da tragédia na boate de Santa Maria, cabe ressaltar que este estudo não buscou acessar a experiência de bombeiros envolvidos diretamente naquele evento. Entendeu-se que a relevância do estudo dizia respeito à vivência singular de uma profissão de assistência em contextos de risco, de modo que a escolha dos participantes não se restringiu ao critério de atuação em uma missão específica.

\section{Procedimentos}

Após a aprovação do Projeto de Pesquisa pelo Comitê de Ética em Pesquisa da Universidade, contatou-se a instituição a fim de se obter a autorização para sua realização. Posteriormente, buscou-se a adesão e a participação voluntária dos profissionais, apresentando-lhes o objetivo e os procedimentos do estudo. Os participantes assinaram o Termo de Consentimento Livre e Esclarecido e concederam, individualmente, uma entrevista semiestruturada, de questões abertas, que foi gravada, transcrita na íntegra e analisada por meio do método de Análise de Conteúdo. Esse é um método utilizado para descrição e interpretação de documentos e textos, cuja análise possibilita atingir um entendimento de significados das mensagens para além da compreensão obtida em uma leitura comum. Acerca da Análise de Conteúdo, Bardin (1977), sua principal proponente, a define como "um conjunto de técnicas de análise de comunicação visando obter, por procedimentos sistemáticos e objetivos de descrição do conteúdo das mensagens, indicadores (quantitativos ou não) que permitam a inferência de conhecimentos relativos às condições de produção/recepção destas mensagens" (p. 42). O estudo valeu-se da releitura proposta por Moraes (1999) da Análise de Conteúdo de Bardin (1977), em que os procedimentos foram realizados a partir das cinco etapas concebidas por aquele autor, quais sejam: Preparação, Unitarização, Categorização, Descrição e Interpretação. Para a discussão dos achados foi utilizado o referencial psicanalítico, mais particularmente da Psicodinâmica do Trabalho, que embasou, justificou e orientou esta pesquisa.

\section{Resultados e discussão}

A idade média dos participantes deste estudo foi de 40 anos e a média de tempo de serviço no Corpo de Bombeiros de 21 anos. A totalidade dos participantes era do sexo masculino e possuía a patente de soldado. De acordo com o método, fez-se, inicialmente, a leitura exaustiva das transcrições das entrevistas. À luz dos objetivos do estudo, definiram-se as unidades de significado que, por sua vez, foram agrupadas em categorias iniciais. Em seguida, em novo agrupamento, estruturaram-se as categorias intermediárias que embasam as três Categorias Finais (Tabela), as quais serão descritas e analisadas a seguir, podendo seu rigor e sua validade serem observados na fidelidade às verbalizações dos participantes e na pertinência da análise das mesmas.

\section{A permanente e incondicional disponibilidade ao outro como marca identitária}

Para Dejours (2011, 2012a), a conquista da identidade, viabilizada pela dinâmica intersubjetiva de reconhecimento no trabalho, está diretamente relacionada à realização pessoal no campo das relações sociais que a prática laboral oportuniza. No relato dos entrevistados, as temáticas relativas às identificações, na constituição de uma identidade profissional, assumiram notável centralidade.

Conforme demonstrado por Freud (1914/2004), o Eu não está dado desde o princípio da vida, ou seja, "o Eu precisa antes ser desenvolvido" (p. 99). Tal proposição representa um cisma histórico no seio do pensamentos moderno na forma de se compreender a subjetividade humana, na medida em que denota $o$ caráter de abertura desta à alteridade. $\mathrm{O}$ Eu é, segundo Hornstein (2009a), "multiplicidade de imagens e enunciados edificantes dos outros significativos que lhe ofertam peças do quebra-cabeças, quebra-cabeças que ninguém somente o Eu pode armar, elegendo as que o ajudam a prosseguir sua construção identificatória" (p. 157). Durante a vida adulta, será o espaço do trabalho o palco privilegiado de trocas com a alteridade, constituindo-se esse em mediador central da 
Tabela

Categorização Inicial, Intermediária e Final dos dados obtidos nas entrevistas com os participantes do estudo.

\begin{tabular}{lrc}
\hline Categorias Iniciais & $\begin{array}{c}\text { Categorias } \\
\text { Intermediárias }\end{array}$ & Categorias Finais \\
\hline
\end{tabular}

Motivos da escolha por ser bombeiros

Ressignificações do ser bombeiro a partir do ingresso

Formação como transição entre a vida civil e a vida militar

Adestramento físico e mental na Formação de Bombeiro

Associação entre ser bombeiro e a vontade de ajudar/salvar o outro

Ser X Estar bombeiro

"Bombeiro é grupo!"

Mais do que profissão, um estilo de vida

O bombeiro não tem a quem chamar/recorrer, é ele que tem que resolver

O risco como inerente à profissão

Diante do risco, a missão fala mais alto

Dicotomia entre veteranos e novatos no fazer cotidiano da profissão

Chamado, adrenalina e sentimento de ser super-herói (um lado da moeda)

O último elo da corrente: a vida de quem não tem a quem chamar

Medo é para ser esquecido

O real da cena é sempre diferente do simulado

Habilidades pessoais e astúcia para resolver o que não fora previsto

Experiências de excesso em contextos marcados por morte e

sofrimento (o outro lado da moeda)

"Todo bombeiro tem uma cicatriz emocional"

Ocorrências com crianças: marcas que calam fundo

A legitimação da dor diante de ocorrências com morte de crianças

Defesas para não se afetar, não enlouquecer e poder seguir trabalhando

Não há espaço para sentimentos, apenas para técnicas

Silêncio e solidão diante das perdas: a palavra sonegada

Efeitos do silêncio sobre a vida pessoal do bombeiro

Defesa estendida: silenciar para a família não saber

Não pensar para poder salvar

Celebrar o êxito total para depois esquecê-lo

O papel da família no reconhecimento e valorização da profissão

Rejeição social ao perfil identitário militar

Reconhecimento por superiores e valorização por parte da Corporação

Considerações acerca do reconhecimento social

Não basta ser bombeiro, há que parecer bombeiro

Limitações na estrutura e consequências no cotidiano de trabalho

Rigidez hierárquica que castra e limita as vontades

Ocorrências grandes e explicitação da precariedade de recursos institucionais

Perspectivas pessimistas quanto ao futuro da Corporação

\section{Suportar o insuportável: a singularidade do enfrentamento da morte e os limites ao heroísmo \\ Marcas singulares de um fazer singular: efeitos e defesas diante do real da morte}

Em meio ao barulho, trabalhar em silêncio

Reconhecimento externo como signo

Expectativas promissoras em relação às mudanças institucionais
A permanente e incondicional disponibilidade ao outro como marca identitária

Os tensionamentos entre o protocolo e o cotidiano de existência

\footnotetext{
Retaguarda institucional ao sujeito que salva: nuances do
}

A estrutura institucional e seus limites

A mudança como esperança e como temor em um futuro não tão distante 
construção, do desenvolvimento e da complementação da identidade do sujeito (Lancman, 2011).

Para os participantes da pesquisa, foram distintos os motivos para a escolha da profissão de bombeiro, mas todos vislumbravam no ingresso na Corporação a possibilidade de se aproximar daquilo que desejavam ser. O participante Teseu narra seu interesse pelo cuidado e pela assistência ao outro: "É de criança, de infância, querer ser bombeiro, brincar de bombeiro, querer salvar, querer ajudar o próximo... No começo, não era bem bombeiro, era uma profissão mais para a parte da saúde, de querer ajudar... Na adolescência, fui mais me identificando 'eu quero ser bombeiro, ver como é que é o serviço dos bombeiros".

Orientando-se pela teoria psicanalítica e considerando que as experiências da infância fundamentam os traços mais estáveis da personalidade dos sujeitos, Dejours (1996) propõe o conceito de ressonância simbólica, como elemento motriz da escolha profissional. Na infância, as teorias explicativas operacionalizam-se, segundo o autor, em experimentações, jogos e teatros com os pais; na vida adulta, o trabalho se prestará a ser também um teatro para a encenação dessas experiências, agora, porém, os parceiros serão outros adultos trabalhadores e o objetivo, que outrora era do prazer do jogo, será de ação no campo da produção. Assim, apresenta a escolha profissional como primeira condição concreta da ressonância simbólica, dependendo esta escolha muito antes do sujeito do que do trabalho a ser escolhido.

Os três participantes da pesquisa, Ulisses, Perseu e Teseu, escolheram se tornar bombeiros e assim permanecem há vários anos. Suas entrevistas revelam profissionais comprometidos que, apesar das dificuldades que enfrentam, seguem encontrando sentido no seu fazer profissional e se definindo a partir desse. Para Sznelwar e Lancman (2011), "o trabalho é um elemento central na promoção do desenvolvimento psíquico e da constituição da identidade" (p. 20). Dessa maneira, em meio às muitas relações intersubjetivas experimentadas, um sujeito pode encontrar, no trabalho, os elementos identificatórios fundamentais para a vivência de sua subjetividade. Nesse sentido, Dejours (2012a) situa que a análise da relação entre subjetividade e trabalho demonstra, à luz da Psicodinâmica do Trabalho, que o trabalho profissional mobiliza toda a subjetividade. Para o autor, "trabalhar não é apenas produzir, mas ainda transformar a si próprio e, no melhor dos casos, é uma ocasião oferecida à subjetividade de provar a si mesma, de realizar-se" (Dejours, 2012a, p. 34). A categoria de sujeito guarda considerável polissemia em Psicanálise, de modo que se faz mister a delimitação desta no âmbito da análise do sujeito trabalhador a que este artigo se propõe. Dejours (2012a;b) volta-se à teoria psicanalítica, mais propriamente ao texto freudiano sobre a pulsão e seus destinos, para afirmar que, no centro da subjetividade, está a sexualidade, isto é, a pulsão como exigência de trabalho imposta ao psíquico, em consequência de sua relação com corpo. $\mathrm{O}$ autor, ao se remeter ao sujeito em sua prática laboral, situa, no entanto, a dupla centralidade da subjetividade que se, de um lado, tem seu advento por meio da sexualidade, do desejo e do amor, ricamente demonstrados pela teoria psicanalítica, por outro lado, pode encontrar sua ampliação por meio da experiência de trabalho. Na investigação da subjetividade, Dejours (2012a) identifica, portanto, o que denominou "paradoxo da dupla centralidade" do sujeito, ou seja, a definição de sujeito está situada, simultaneamente, entre o real do mundo que impõe dificuldades ao trabalho - podendo levar o sujeito ao sofrimento e à criação do trabalho e, consequentemente, de si mesmo - e o inconsciente que, via pulsão, impõe exigências de trabalho elaborativo ao psíquico.

Nessa direção, na transição entre um modo de vida civil e a vida militar, os elementos subjetivos destacam-se. Ulisses ilustra, sobremaneira, seus lutos para aprender os particulares ritmos e normas de uma sociedade militar:

O curso de formação nada mais é do que um adestramento. [...] Aquele período ali é um período de transição, tu vai sair de uma vida pra entrar na outra. Corria quase todos os dias, fazia flexão de braço, abdominal. [...] Se errava alguma coisa, você fazia isso. [...] Então ele te adestra o físico e adestra... Hoje entendo que tem que ter, até por causa do nosso regime.

Hornstein (2009b) refere um psiquismo aberto, cujas transformações e atualizações se operam com base nas constantes trocas desse com o meio em que o sujeito se insere. O sistema psíquico, segundo o autor, é aberto a ponto de se atualizar, mantendo suas características identitárias. Na fala de Ulisses, as transformações pelas quais precisou passar resul- 
tam em crítica daquilo a que tivera que se "submeter". Quando cede ao "sistema" e nomeia como necessários esses procedimentos, demonstra sua forma de se reconciliar com seus novos traços identificatórios de militar e com a instituição que representa. De acordo com Lancman (2011), o trabalho cumpre importante função psíquica ao servir de alicerce à constituição do sujeito e de sua rede de significados. Para a autora, os processos de reconhecimento, de gratificação, de mobilização da inteligência, vivenciados no trabalho, mais do que relativos à realização das tarefas, estão ligados à constituição da identidade e da subjetividade do trabalhador. Tal aspecto pode ser ilustrado, com precisão, na ideia que quer transmitir Perseu, ao afirmar, convictamente: "Bombeiro não é profissão, é um estilo de vida".

Os entrevistados reportam-se à distinção entre o "ser bombeiro", ao que atribuem grande valor, relacionado ao comprometimento de profissionais que priorizam as missões de salvamento, em detrimento à própria vida, se necessário, e o "estar bombeiro", relativo àqueles que não estão plenamente comprometidos, conotando, inclusive, uma falha na identidade profissional destes. É Perseu quem explicita esta distinção: “Tem pessoas que só estão nos Bombeiros; tem pessoas que são bombeiros. [...] Estes vestiram a camiseta, vão lá, resolvem, correm atrás. Aqueles não vestiram a camiseta, não incorporaram esse estilo de vida e ficam esperando que os responsáveis resolvam". O termo "incorporar", de que se vale Perseu para distinguir dois tipos de profissionais, assevera a relevância das identificações para essa classe profissional. O narcisismo revela sua influência tanto nas representações identitárias quanto no investimento de libido para a manutenção destas. Segundo destaca Hornstein (2009b), é o narcisismo que viabiliza ao sujeito um movimento de centramento de suas representações identificatórias.

Os participantes associam ser bombeiro à vontade ou à necessidade de ajudar as outras pessoas. Tal característica é arrolada tanto quando justificam a escolha pela profissão como quando falam do que lhes dá satisfação na carreira, incentivando-os à permanência nesta. Perseu encontra valor na experiência de ajudar, relacionando-a à satisfação de ser bombeiro, quando diz: "Só quem está nos Bombeiros tem a noção da satisfação. [...] Fazer a diferença entre a vida e a morte de uma pessoa. [...] A questão de ajudar, da missão de ajudar, não é só de salvar, é de ajudar".
Diante de tal relato, pode-se, com Dejours (2011), concluir que o prazer, a saúde e a realização de si no processo de construção da identidade oportunizado pelo trabalho são ganhos com relação ao sofrimento, por tanto tempo assumido como componente básico a caracterizar as relações laborais. Percebe-se, todavia, ser a solidão conteúdo presente no relato dos entrevistados, identificada, sobremaneira, na proibição de expressar fragilidade, medo, dúvida, sofrimento. Mesmo após ocorrências com mortes e/ou importantes perdas, é o silêncio e a reclusão em si mesmo que costumam imperar. Em contraponto com essa característica, talvez como forma de amainar a solidão do silêncio que precisou ser aprendido, Perseu remete-se à importância do grupo, que cumpre, também, importante função identitária: Segundo esse participante, "toda e qualquer ocorrência é grupo. Tu não faz nada sozinho. A segurança dele depende de mim. Eu cuido ele; ele me cuida. Então, a gente cria uma visão de coletivo, de pensar em um bem coletivo, não em um bem meu só".

A experiência de pertencimento ao grupo parece aplacar parcialmente a ameaça de desamparo, tão peculiar ao humano e particularmente presente em uma profissão cuja prática se dá em contextos de risco e de morte. Dejours (2011) aponta para a cooperação no trabalho como sendo a vontade de as pessoas trabalharem juntas e de superarem coletivamente as dificuldades. $\mathrm{O}$ autor considera que, para que haja cooperação, há a exigência de relações de confiança entre os indivíduos. Certamente, não há maior confiança do que a convicção de segurança compartilhada por colegas que, por regra, preservam a vida um do outro. "De repente, um se amarrou numa corda e se atirou dentro do poço [onde estava a criança], não sabia o que tinha, sem lanterna, sem nada... Nós segurando um cabo" (Teseu).

$\mathrm{O}$ atendimento a demandas nas quais de seu adequado desempenho depende a vida do outro representa importante baliza a delimitar a identidade do bombeiro. No discurso dos entrevistados está posto que, uma vez chamados, tudo passa, intransferivelmente, a deles depender. Os bombeiros ocupam a difícil posição de último elo de uma corrente, não tendo eles a quem recorrer.

Tem que entrar [no fogo], tem que entrar. É tu que tem que entrar. Tu vai chamar quem? "Ah, vai chamar o bombeiro?!”. Não. O bombeiro sou eu! 
Eu tenho que entrar. Às vezes, tu não sabe o que vai fazer ou o que tem lá dentro, o que te espera. Aquela pessoa está dependendo de ti. [...] É tu que tem que resolver (Teseu).

Paradoxalmente, o profissional bombeiro, como um personagem heroico, parece fazer a escolha por não ter escolha a fazer. A escolha por ser bombeiro implica em não poder/conseguir se omitir, mesmo diante dos grandes riscos, tal como nomeia Perseu: "Posso decidir não entrar, não vou ser penalizado, mas aí vem a missão. Então tu vai além, tu expõe tua vida ao risco. Esquece tua família, esquece teu filho, esquece tua esposa. Tu esquece! Te expõe demais, te expõe mesmo".

Para o bombeiro que é bombeiro, segundo os entrevistados, não pode haver espaço à dúvida. As entrevistas são ricas em conteúdos que remetem à realização do ideal - ampla e socialmente valorizado - de ajudar/salvar o outro, no qual se encontra satisfação de ordem narcísica, ao custo de enfrentar os riscos reais do fazer. Se há dificuldades em enfrentar grandes riscos, é, também, nelas que reafirmam a identidade de herói, experimentando a onipotência e certo fascínio pelo desafio de entrar em locais de onde todos fogem. "O que faz com que a gente vá, e isso influencia bastante, é a adrenalina. A adrenalina vicia, ela é viciante e isso é comprovado" (Perseu). "Adrenalina vai lá em cima e tu não... Tu te sente o super-herói. Tu sabe que não é, mas te sente o super-herói que tem que resolver" (Teseu). "A gente não é super-herói, ser super-herói é muito fácil, ele tem superpoderes. A gente não tem superpoderes. A gente é uma pessoa comum. [...] Mas me cobrei muito de fazer alguma coisa a mais, o que eu fiz de errado, o que eu podia ter feito" (Perseu).

O dilema existente entre ter de ser herói na missão e, concomitantemente, reconhecer as fragilidades de ser humano produz um conflito que gera sofrimento nestes profissionais. Dessa maneira, a diferença identificada no modo de atuar dos bombeiros novatos é denunciada por um participante veterano, ao oscilar entre a crítica e a aprovação da realização dos procedimentos pelos jovens.

Eles [os novatos] pensam muito, raciocinam muito. E nós [veteranos] não [...]. Eles se preocupam muito em analisar a situação, para a gente não perder a vítima e nós também a nossa vida.
Nossa preocupação é toda com a vítima, tirar ela dali, de qualquer jeito. [...] O certo seria, no momento, toda a preocupação. Preservar e se preservar. Mas nós não. [...] pensamos mais no serviço (Teseu).

Acompanhando a sensação de heroísmo que incentiva a ação, por vezes impulsiva, está, também, a ameaça de perder a própria vida. Na cautela dos novatos, Teseu constata a adequação da conduta durante a ação, uma vez que, quando fala a respeito desta, reconhece a existência de risco à vida do bombeiro. A especificidade da prática laboral de um bombeiro, calcada nesses ideais identitários, impõe a necessidade de lançar mão de recursos subjetivos para administrar impasses oriundos do descompasso entre o protocolo e a realidade. Nesse cenário, apresenta-se a segunda Categoria Final do estudo.

\section{Os tensionamentos entre o protocolo e o cotidiano}

Tão importantes quanto as proteções materiais que revestem o corpo são os recursos psíquicos para enfrentar cenários marcados por destruição e perdas, inclusive de vidas humanas. Para além da farda antichamas, há um sujeito passível de sofrer efeitos diante do vivido. Se um lado da moeda estampa as vivências de heroísmo dos bombeiros, a outra face constitui-se das experiências de excesso vivenciadas em contextos de morte e sofrimento. É notável no relato de Ulisses o excesso experimentado, quando descreve sua primeira missão de salvamento. Logo após sofrer o trote dos veteranos, o participante teve seu primeiro contato com o sofrimento de uma vítima de incêndio e, na sequência, com a morte desta.

Fiquei agarrado na mangueira para não me bater, e aí nisso eu escuto um senhor que morreu, gritando. Horrível! [...]. Primeira vez que eu tinha visto isso, nunca tinha visto morto, nem chegava perto. [...] Daí eu vi aquele senhor ali todo rachado e o cheiro ficou uns três, quatro dias. Eu não sei como explicar, é um cheiro assim de carne assada, molhada, sem sal, sabe? [...] Eu entendi que o serviço já não era, não é essa maravilha. Você só vai trabalhar quando alguém vai perder completamente tudo. Você vai ver o que há de pior no mundo. Você pega um acidentado 
que morreu ali na estrada. Tu chega lá, a pessoa está quente ainda, mas está morta (Ulisses).

Um bombeiro, quando atende ao chamado, não sabe exatamente o que o espera na ocorrência, tampouco tem garantias de que a técnica em que foi treinado dará conta da missão, no encontro com o real, isto é, com aquilo que se lhe impõe, a despeito de qualquer protocolo. Será somente durante a realização do trabalho efetivo que o trabalhador deparar-se-á com os limites de sua técnica, experimentando, então, de forma particular, o tensionamento do encontro entre o sabido/treinado e o imprevisível. Segundo Dejours (2012b), a lacuna existente entre o prescrito e o efetivo é descoberta na experiência do real do trabalho, não sendo nunca preenchida em definitivo, mas sobrevindo sempre em forma de dificuldades e imprevistos. Tal diversidade surge na descrição de Perseu, quando afirma que: "Cada cenário é diferente. [...] Nunca é igual, nunca! Pode ser incêndio, nunca é igual, nunca, nunca é igual".

Uma das formas de defesa frente ao imprevisível de uma missão parece estar na crença inicial de que o treinamento recebido os investe das condições necessárias e suficientes para dar conta de toda e qualquer ocorrência, evidenciada na grande prontidão com que atendem aos chamados. Revela-se, discretamente, na fala dos participantes, que uma das saídas encontradas, ao se valerem do senso de prontidão e do valor atribuído à missão, parece estar no fato de não priorizarem o imponderável do risco a que se submetem. O que não significa que não percebam e não reconheçam o perigo. Perseu ilustra essa constatação ao declarar que: "Por mais que tu tentes simular, no treinamento, uma ocorrência, esse simulado nunca vai chegar a ser igual a ela. A real cena vai ser diferente".

O preenchimento da lacuna existente entre o preconizado pelo protocolo e o trabalho efetivo, sublinhado por Dejours (2012b) como definidor do que seja trabalhar - no caso dos bombeiros, o salvamento de um outro -, somente é possível porque há uma subjetividade em ação. $\mathrm{O}$ autor esclarece que é por meio daquilo que o sujeito acrescenta às prescrições, como forma de atingir os objetivos que lhe foram confiados, que o trabalho acontece e se define. O protocolo é executado por um sujeito, sendo também esse que enfrenta a realidade, inclusive quando há incidentes. Enfatiza-se que trabalhar, na concepção dejouriana, é fazer frente ao real, sobremaneira naqueles pontos em que o protocolo não alcança, mas algo precisa ser feito. Perseu parece não conseguir lidar com a impossibilidade de salvar uma jovem vítima de acidente automobilístico, fato que o faz experimentar o sentimento de impotência, diante do qual debate-se em busca de explicações, na solidão do alojamento. "Começa a vir a questão de impotência, de frustração. O pai da vítima me agradeceu, fiz o máximo, mas não consegui reverter, é a questão da impotência, da frustração, de tu fazer o máximo, mas, dada a gravidade do acidente, tu não conseguir... Aí, eu comecei a chorar" (Perseu).

Há algo que resiste à técnica, que é incontornável. Aí o humano encontra-se com o real. Segundo Dejours (2012b), quando todo o saber e toda a técnica não dão conta de vencer a resistência do mundo, está-se no real. De repente, o protocolo e os procedimentos exaustivamente treinados, que pareciam representar garantias diante do risco, mostram-se insuficientes. O real, segundo Dejours (2012b), faz-se "conhecer, por aquele que trabalha sob a forma de fracasso, como experiência desagradável, dolorosa, ou como sentimento de impotência ou angústia [...] é sempre afetivamente que o real do mundo inicia sua manifestação para o sujeito" (p. 39). Mediante a indagação de como é ser chamado para resolver o problema e ter que lidar com a impotência, Perseu responde com notável pesar: "É frustrante demais, tu ficas pensando: O que posso fazer? O que posso melhorar? O que eu fiz de errado? Tu começas a se perguntar um monte de coisas".

É Dejours (2011) quem afirma que "o trabalho é, por definição, humano, uma vez que é mobilizado justamente ali onde a ordem tecnológica-maquinal é insuficiente" (p.79). Essa posição do autor sustenta-se na singularidade com que o humano é capaz de ultrapassar o que está dado, prescrito, previsto. Se o real da cena é sempre diferente do simulado, como expressado por Perseu, revela-se imprescindível um humano que pense e não uma máquina que somente execute procedimentos. Evidencia-se, diante disso, que é o sujeito quem salva, não o protocolo. Aonde o protocolo não chega, devido às mazelas do real, será o sujeito, por meio de sua singularidade, que construirá soluções inéditas. Como forma de superar o real, que impõe barreiras ao trabalho do sujeito, Dejours (2012b) aponta como saída a inteligência astuciosa. Segundo o autor, essa é a inteligência que corre paralela aos protocolos e cuja marca é a astúcia da cria- 
tividade subjetiva, que se preocupa com a eficácia e age com liberdade. De acordo com Teseu, "tu tem que pensar, e tudo isso aí é rápido. É um jogo de fração de segundos. [...] Isso a gente pega com o tempo, pega com a prática".

A fala de Teseu aponta a relevância das habilidades pessoais e da astúcia na resolução de situações não previstas pelo protocolo, mas que se apresentam em seu trabalho cotidiano. Para Dejours (2012b), "a inteligência da prática é obtida mediante um esforço obstinado que mobiliza toda a subjetividade, ultrapassando-a mesmo" (p.50). No ponto em que o protocolo atinge seu limite, o humano apresenta-se como imprescindível para a realização da missão. Dejours (2012a,b) propõe o "trabalho vivo" como a capacidade do sujeito de reagir às limitações encontradas no campo laboral, sendo desafiado a construir novas soluções e tendo, com isso, a oportunidade de transformar o trabalho e a si mesmo. Logo, conforme o autor, por meio do trabalho vivo, o sujeito resiste e faz frente aos fracassos impostos pelo real.

Na medida em que a execução da missão exige que os profissionais bombeiros se exponham a cenas com grande carga emocional faz-se necessária uma espécie de blindagem protetora que viabilize a ação. $\mathrm{O}$ medo, por exemplo, deve ser esquecido. $\mathrm{O}$ bombeiro precisa, portanto, defender-se de afetos que possam impedi-lo de cumprir a missão. Tal defesa, no relato dos participantes, costuma ser efetiva e, dessa maneira, garantidora da integridade emocional do profissional que consegue realizar a tarefa a que se propõem. Todavia, há situações em que a defesa falha e algo irrompe, deixando marcas profundas. "Esse negócio de que não teve nenhuma ocorrência que marcou é mentira. Todo e qualquer bombeiro normalmente ficou com alguma cicatriz..." (Perseu).

Mais do que uma cicatriz, entendida como marca historicizada, isto é, simbolizada e, portanto, portadora de relativa flexibilidade, a "cicatriz" a que se refere Perseu parece remeter à rigidez de um queloide. Schenquerman (2010) propõe como metáfora extensiva ao psiquismo a existência de distinções entre cicatriz e cicatriz-queloide. Segundo considera, como efeito residual do excesso vivido, pode surgir uma cicatrização ao modo de cicatriz-queloide, uma região de insensibilidade pelo engrossamento da pele, dado os contrainvestimentos massivos. Se a cicatriz é plástica, discreta e não deixa limitações ao movimento, a queloide faz-se notar por todos como imagem de um fun- cionamento rígido, marcado pelo empobrecimento da funcionalidade, extensiva a todos os níveis do psiquismo (Schenquerman, 2010). Notadamente, de acordo com os entrevistados, há determinados tipos de ocorrências especialmente marcantes, nas quais os mecanismos protetivos revelam-se insuficientes e o psiquismo fica mais vulnerável aos estímulos advindos da realidade. Para Perseu, "tem umas ocorrências bem mais complexas. São ocorrências bem pontuais, que não são rotineiras. Bem pontuais mesmo, envolvendo criança... Tirando essas com criança, foi essa da Kiss. Todo esse tempo que eu estou, foi a da Kiss".

O participante Perseu, mesmo não tendo atuado na ocorrência da Boate Kiss, reporta o impacto sofrido, comparando-o às ocorrências que envolvem crianças, explicitamente assumidas como "complexas" e capazes de, ao romper com os mecanismos protetivos, causar significativa afetação no bombeiro. Ainda que distante daquela vultosa ocorrência, Perseu recolheu-se e chorou. No texto Introdução à psicanálise das neuroses de guerra, Freud (1919/2006) indaga as razões de se produzirem neuroses de guerra, com características traumáticas, nos soldados que estavam na retaguarda, ao passo que essas não se produziam, muitas vezes, naqueles que estavam no front de combate. Inaugura-se então, conforme Bleichmar (2010), a problemática do traumático para a Psicanálise.

De modo particular, segundo o relato dos participantes, o fracasso no salvamento de crianças parece ter, mediante falha do mecanismo protetivo que viabiliza a ação, efeitos nefastos sobre os bombeiros, deixando-lhes marcas dolorosas, que os põem indefesos diante dos limites de seu heroísmo e dos reais limites da vida. Se o encontro com o real se viabiliza pela utilização de mecanismos protetivos que tendem a blindar afetivamente o bombeiro, tais recursos, diante da morte de crianças, parecem insuficientes, de onde podem decorrer importantes cicatrizes, queloides ou não.

Faleceram as três crianças, morreram queimadas. Num incêndio que marcou muito, que até hoje eu me lembro... da criancinha, do pequeninho, do bebezinho, que parecia uma bonequinha. [...] Tem horas que a gente lembra do rostinho daquela criança e parece uma bonequinha. [...] Do rosto, até hoje. Não tem como esquecer (Teseu). 
Freud (1920/2006) propôs chamar de traumáticas as excitações externas que possuíssem intensidade suficiente para romper o "escudo protetor" de que se vale o psiquismo e que opera de modo eficaz em circunstâncias normais. Na medida em que é inviável impedir que o excesso de estímulo inunde o aparelho psíquico, resta tentar lidar com esse excesso, capturando-o e o ligando psiquicamente para poder processá-lo. Todavia, quando o sujeito não consegue estabelecer ligações entre o excesso vivido e a rede de suas significações, a tendência é de que, em lugar da integração simbólica da experiência, haja repetições da cena traumática. Teseu segue lembrando-se do rosto do bebê que encontrou queimado: "Lembrei-me da guriazinha. O rostinho perfeito. Eu vi o rostinho. Não sei se faz 12 ou 15 anos e eu me lembro perfeitamente".

Diante da constatação de manifestações repetitivas do sujeito que, em lugar de prazer, fazem-se acompanhar de sofrimento, Freud, em 1920, introduz a problemática do trauma como um fenômeno psíquico no qual a vigência do princípio do prazer parece claudicar ante o perigo externo (Uchitel, 2011). No entanto, a proposição psicanalítica difere substancialmente das perspectivas teóricas e clínicas que buscam apenas no evento real a etiologia do sofrimento do sujeito. Enfatiza que as marcas de uma experiência serão sempre singulares e relativas ao aparato psíquico do sujeito que a vivenciou. Perseu ilustra a singularidade do trauma quando, ao se culpar, revela as marcas não da cena trágica de um acidente automobilístico tampouco da tentativa de salvamento da jovem que faleceu vitimada por esse, mas do gesto de gratidão do pai dela, diante daquilo que representava um fracasso em sua ação como bombeiro. "A filha dele estava morta, mesmo assim ele me agradeceu um monte, entendeu? [...] A filha dele tá morta e ele me agradecendo. Eu não consegui... Entendeu? Aí é um turbilhão, entendeu? Esse aí chocou bastante" (Perseu).

A perda de crianças em ocorrências configura-se em uma legitimação "institucional" do sofrimento psíquico. Enquanto se indagam acerca do que do protocolo figurou errado na ação, não integram a intensa carga afetiva da experiência vivida como sendo própria, na condição subjetiva que, apesar da rigidez das defesas mobilizadas, permite-lhes atuar. A consequência mais direta é a tentativa de não pensar a respeito do ocorrido, tampouco conversar entre si, de maneira que o silêncio segue operando como regra e a serviço da defesa. Nesse sentido, quando indagado como faz para lidar com seus sentimentos e se conversa sobre eles, Perseu, aparentemente surpreso com a pergunta, responde: "Não! Eu não converso! Isso tudo aí é mecanismo de defesa, entendeu? Tu te abala, fica chocado, mas tem que ser aquele negócio momentâneo: 'puf', deu, sai. Se tu ficar com aquele negócio contigo, tu não tem condições, não vai ter condições. [...] Isso faz parte, tu tem essa carapaça, entendeu?" (Perseu).

Sutilmente, essa carapaça, que, à primeira vista, protege o psiquismo dos excessos advindos de seu exterior pode levar a um enrijecimento, igualmente perigoso, do sistema psíquico, ao custo de seu empobrecimento e, consequentemente, do aumento de sua vulnerabilidade aos excessos vividos. Retomando a analogia utilizada por Freud, em 1920 (2006), de uma vesícula de matéria viva, Figueiredo e Coelho Junior (2008) gizam a importância do desenvolvimento de uma crosta que amorteça e filtre aquilo que incide sobre o organismo e que, simultaneamente, demarque fronteiras de um território próprio. Ressalvam, todavia, que tal crosta protetora não é suficiente, podendo romper-se diante de um episódio traumático, o que exige uma segunda defesa, uma retaguarda. Essa retaguarda está na condição de uma quantidade de energia colocada em reserva, disponível para fazer frente à invasão de um excesso de energia livre, e que somente terá sido acumulada no caso da crosta não ser de todo fechada, a ponto de ter impedido a entrada e o acúmulo de investimentos no espaço próprio (Figueiredo, \& Coelho Junior, 2008). Descortina-se que a defesa efetiva, isto é, aquela que possibilita a integração da experiência vivida por meio de operações de ligação da energia livre que invade o sistema, via construção de representações, ocorre nos pontos em que o vivido pode ser sentido e processado como tal. Logo, dada a rigidez, ao tentar se defender, o psiquismo revela sua fragilidade, sua escassez de reservas, produzindo-se desse fatídico encontro não cicatrizes plásticas e historicizadas, mas queloides rígidas, a exemplo das defesas que lhes deram ocasião. Perseu explicita a necessidade de se valer de mecanismos de defesa para poder suportar os excessos, sobremaneira afetivos, do cotidiano de trabalho.

Isso também faz parte do mecanismo de defesa, tu não pode ficar pensando demais. Isso aí é um mecanismo de defesa, tu ser frio na ocorrência, não se envolver sentimentalmente com a vítima. 
[...] Esse negócio de ser frio, atender uma ocorrência grave, complexa, e voltar tranquilo, como se não fosse nada. Isso aí tem que ter. É um mecanismo de defesa. Se não tivesse isso, todo bombeiro ia surtar, ia enlouquecer. Imagina se toda ocorrência que tu atender, tu te envolver sentimentalmente com as vítimas (Perseu).

A Psicodinâmica do Trabalho explorou a utilização de mecanismos de defesa individuais e estratégias de defesa coletivas (Lancman, \& Uchida, 2003). Tal disciplina cuidou de, para além da investigação das formas de adoecimento mental relacionadas ao trabalho, aprofundar as compreensões das estratégias de defesa de que se valiam os trabalhadores para se manterem equilibrados, com a ressalva de que o aparente equilíbrio poderia albergar significativo sofrimento psíquico (Lancman, \& Uchida, 2003). Perseu indica que o bombeiro não pode pensar demais, cabendo-lhe focar na técnica e cumprir o protocolo. Todavia, a assepsia do protocolo parece encontrar seu limite em cenas nas quais as fantasias de uma morte distante não podem mais ser sustentadas. Conforme Perseu: "Tem ocorrências que tu se envolve automaticamente, pode ter cinquenta anos de bombeiro que se envolve. Principalmente ocorrências envolvendo crianças, aí tu projeta se tem primos, se tem filhos".

O silêncio que se impõem ao experienciar missões perigosas e que se estende ao não compartilhamento familiar do cotidiano laboral, encontra reforço no risco que os participantes atribuem ao pensar, diante da ocorrência. Reconhecem o risco de sua atividade, mas, diante da necessidade de um rápido agir, atribuem ao pensar uma fragilidade em sua competência. Diz Perseu: "Na ocorrência, tu não pensa. [...] Se pensar, nem sai”. E, também, Teseu: "Se parar para pensar, para raciocinar, não entra [no fogo]. É, não entra. [...] Porque é uma loucura, se tu parar para analisar, não entra".

Contrastando com as muitas dificuldades enfrentadas, nas ocorrências em que o êxito é total, há celebração. Porém, depois da efusiva comemoração, é o esquecimento que deve operar. Novamente, é o silêncio acerca do vivido, mesmo que exitoso, que precisa se restabelecer. A fala de Ulisses aponta para a contenção de emoções e para o silêncio que precisam ser aprendidos: "A estrutura vai te moldando a ser um cara mais contido, bem mais contido. Não expressar o que sente! Não é expressar, é não expressar mesmo".
A inexistência de "acompanhamento" institucional para singulares demandas leva o profissional bombeiro a criar estratégias de enfrentamento solitárias para os excessos vividos que parecem ter como consequências o fracasso das relações pessoais e familiares e o estado de esgotamento. É Teseu, veterano com acentuado senso crítico, que alerta para a necessidade de acompanhamento profissional aos bombeiros: "Depois, a gente sai do serviço e não tem acompanhamento nenhum. Tinha que ter um acompanhamento. Não tem. Fica aquilo ali muito tempo [...] Não é só eu que estou falando, nós todos somos assim: têm um problema".

Conforme se demonstrou, o silêncio que, na qualidade de mecanismo protetivo, salvaguarda o sujeito de pensar sua prática e, com isso, angustiar-se, também pode instaurar o traumático. Se o bombeiro não pode "pensar" para não sofrer, para não "enlouquecer", sonegando a si mesmo a palavra sobre o vivido, também lhe fica sonegada a elaboração de experiências cotidianas e singulares que podem fomentar condições de plasticidade psíquica. No tensionamento entre o protocolo e o cotidiano, fica evidenciado, portanto, que é o humano, a partir da sua subjetividade, que salva e o faz onde é possível pensar criativamente e se pensar como sujeito. Se o trabalho vivo, proposto por Dejours (2012a;b), relaciona-se a resistir aos fracassos impostos pelo real, pensar o fazer, que é sempre subjetivo, abre a possibilidade de qualificar a ação e de, na qualidade de sujeito, construir soluções criativas onde o protocolo não alcança. O bombeiro, ao pensar sobre o que sente, já não mais se limita à carapaça rígida da fantasia de onipotência, abrindo-se para esse profissional a possibilidade de se cuidar, ser cuidado e, efetivamente, cuidar do outro. O papel inexorável da instituição Corpo de Bombeiros, no que diz respeito à manutenção das motivações e dos movimentos identificatórios dos bombeiros bem como sua possibilidade de operar como espaço de retaguarda diante dos impasses que marcam esta profissão, é tema da terceira e última categoria a ser apresentada.

\section{Retaguarda institucional ao sujeito que salva: nuances do reconhecimento externo e do amparo ao cuidador}

No âmbito laboral, o reconhecimento dirigido ao sujeito é, primordialmente, dirigido à instituição que esse representa. Quando um bombeiro está em ação, há um sujeito implicado com toda a sua subjetivi- 
dade, mas é em nome da instituição que ele atende ao chamado e atua. Desse modo, ao tematizar o reconhecimento e sua relevante função de lastro identitário, a instituição, com todas as insígnias identificatórias que oferta aos sujeitos que dela participam, assume notável centralidade.

As falas dos participantes apontam para o conflito existente entre a identidade de bombeiro, fortemente ligada ao salvamento e à ajuda ao outro, e sua insolúvel relação com a Brigada Militar, instituição prioritariamente de policiamento e combate ao crime. Essa relação não é estabelecida somente pela população, mas também pelos profissionais que se comparam com os policiais como forma de, ao se autodescrever, marcarem diferenças. Teseu tece significativas considerações acerca do reconhecimento social da profissão: "Tu não vê muito falarem de bombeiros. [...] As pessoas pensam muito em segurança pública, pensam muito em polícia militar na rua. Os bombeiros, eles esquecem".

O descaso social, denunciado por esse participante, pode ser notado, igualmente, pela referência unânime dos entrevistados à escassez de equipamentos de proteção para o atendimento das ocorrências, fato especialmente grave e passível de consequências incontornáveis. Perseu, por sua vez, refere não esperar reconhecimento de outrem tampouco condecorações honrosas, por se sentir gratificado pelos resultados imediatos do trabalho realizado. "Não é porque aquelas pessoas não incentivam, não me dão elogio, que eu vou desistir. É pela missão, entendeu? Não é pelas honrarias, aparecer na mídia, ser destacado em formatura. [...] É pessoal, faço para mim" (Perseu).

Ainda que os familiares sejam preservados dos detalhes das ocorrências, o cotidiano de dedicação ao bem do outro é conhecido e fortemente valorizado, em especial, por cônjuges e filhos. Tal fenômeno exerce importante influência na manutenção da motivação por seguir na carreira, bem como cumpre relevante função identitária, sobremaneira por estar alinhado aos ideais de que os familiares parecem também compartilhar. "Para o meu filho, eu sou um herói, eu sou aquele... 'ah o meu pai lá é um herói, salva as pessoas, ajuda os outros'. Então, eu me sinto bem, me sinto gratificado, mesmo com todos esses problemas" (Teseu).

Essa expressiva fala de Teseu remete a achados de estudos (Gonzales et al., 2006; Monteiro et al., 2007; Natividade, 2009) de como, apesar dos riscos a que ficam expostos e da forte carga emocional decorrente das situações vivenciadas, a profissão de bombeiro costuma ser experimentada como fator de significativa realização pessoal, ancorado em reconhecimento social e apoio por parte da família. O tema do reconhecimento reaparece na alusão de Ulisses à valorização por parte da Corporação, todavia em sua negativa. "Tu é construído de frustrações. Elas que te ajudam a encarar as coisas e fazer e crescer. Então, esse regime é pior que o do pai, né? O pai serve para frustrar você e para você ter uma conduta. Aqui, tu é castrado. Por isso que o regime aqui é castrense, porque é castrado sempre".

Para Ulisses, a instituição impõe limites aos seus integrantes, frustrando-os em seus desejos singulares, sem, contudo, ajudá-los a crescer, em contraste com o que ocorre no interior do grupo familiar. A instituição não somente impõe limites aos seus integrantes, como ela própria depara-se com preocupantes limitações que colocam em risco a realização de sua missão e, também, a vida de seus profissionais. Os participantes aludiram a limitações na estrutura que acarretam consequências no cotidiano de trabalho. "A frustração maior do Corpo de Bombeiros é tu não ter condições de estrutura, de logística. Tu querer fazer as coisas, ter vontade, ter a mão de obra, mas não tem estrutura! [...] Independente dessas deficiências, não vou jogar a toalha, não vou parar" (Perseu).

Essa fala de Perseu conota a grande frustração sentida por profissionais comprometidos com os objetivos de seu trabalho e que se veem diante de significativas deficiências estruturais que dificultam suas tarefas e os expõem ao risco. Implícita está a perversidade social existente em exigir desses profissionais prontidão no atendimento aos chamados e desempenhos irretocáveis, quando a eles não estão garantidos os insumos básicos para a realização do trabalho a que se propõem. As limitações estruturais, devido, sobremaneira, à precariedade de recursos, evidenciam-se em ocorrências grandes, nas quais as consequências podem ter proporções desastrosas e de ampla repercussão pública, conforme exemplifica Teseu ao afirmar que "nesses incêndios grandes tiveram que chamar gente de tudo que é lado. O certo não seria”.

As instituições possuem, segundo Kaës (1991), valor constitutivo para o psiquismo dos sujeitos que as compõem. O autor aponta para uma aderência narcísica ao objeto institucional, sinalizando que um 
sujeito se estrutura como humano também por sua inserção institucional. Integrar uma instituição, portanto, implica em importantes reflexos sobre o narcisismo do sujeito. Claro com isso está que mudanças na instituição produzirão, não necessariamente de forma fácil, novas identificações e ressignificações nos vínculos institucionais. Bombeiro veterano, incomodado com as transformações institucionais, Teseu revela perspectivas pessimistas quanto ao futuro da Corporação que integra. "Está mudando o perfil. Se continuar assim, não sei o que vai ser dos Bombeiros daqui um tempo. Os bombeiros vão tentar apagar o fogo pelo laptop. O fogo está lá e eles vão estar aqui no... [ri]. [...] Já posso me aposentar, mas vou ficar mais 1,2 anos. Mas a preocupação é grande com essa mudança".

Em consonância com o teorizado por Kaës (1991), a aderência narcísica ao objeto institucional explicita-se em Teseu na forma de resistência às mudanças que já se operam nos modos de atender às ocorrências e que põem em risco suas identificações com a instituição, incidindo diretamente em seu narcisismo. Contrastando com essa percepção, estão as expectativas promissoras que as mudanças portam para os demais participantes, com destaque para as transformações na estrutura institucional que se afiguram no horizonte. Para Ulisses, "na verdade, vão criar uma outra instituição. (...) As cabeças vão mudando e vão entrando pessoas com mais conhecimento, com mais possibilidade de diálogo".

Em face do exposto pelos participantes, as mudanças que se descortinam parecem representar momento especialmente promissor para a consolidação identitária do profissional bombeiro. Se o reconhecimento do trabalho realizado é assumido pelo trabalhador como reconhecimento de si mesmo, portanto significativas implicações identitárias para este, parece se desvelar que o reconhecimento do sofrimento subjetivo pela instituição oportunizaria defesas mais saudáveis aos seus integrantes. O desafio estaria em articular os importantes recursos de defesa do sujeito, ou seja, a primeira defesa, a "carapaça”, com os recursos institucionais, uma espécie de segunda defesa, que oportunizaria aos sujeitos a consolidação da energia posta em reserva necessária para fazer frente às intensidades do real a que se expõem. Exortam Perrone e Moraes (2014, p. 33) que, "onde há uma fratura é preciso introduzir golpes de palavras e, nesse sentido, o traumático é história do presente, o passado do presente, sua genealogia, a particularidade disruptiva". Precisamente neste ponto, a instituição concentra relevância como fator protetivo do psiquismo de seus profissionais. Nas fraturas ocasionadas pelo que não pôde ser pensado, como forma de se proteger sob a carapaça que permitiu enfrentar o fogo, golpes de palavra podem oportunizar a composição de uma história de um presente profissional, um passado do presente em que a particularidade possa irromper como paradigma, mediante reconhecimento e amparo àquilo que é subjetivo.

Articular os recursos do sujeito com os recursos institucionais é oportunizar plasticidade psíquica onde poderia existir apenas rigidez. Assim como os equipamentos de proteção, sejam roupas antichamas, capacetes ou cilindros de oxigênio, se forem demasiadamente pesados, podem comprometer a mobilidade e a agilidade, defesas do Eu muito rígidas e estereotipadas podem inviabilizar a ação do sujeito e lhe causar intenso sofrimento, senão a própria morte, considerando-se o risco a que se expõe.

\section{Considerações finais}

Buscou-se lançar luz sobre as singularidades relativas à escolha e ao exercício cotidiano de uma profissão que tem no cuidado e na assistência ao outro suas balizas definidoras. No relato dos participantes, a identidade de bombeiro esteve, durante todo o tempo, associada à ajuda ao outro, ao compromisso em salvar vidas, ao reconhecimento da força de grupo, tendo no risco assumido característica inerente à profissão. Em contraste com a desprezada posição do "estar bombeiro", o "ser bombeiro", onipresente nas falas dos participantes, relaciona-se a "cumprir a missão" a qualquer preço, isto é, enfrentar os perigos, mesmo que desconhecidos, sem nunca recuar, sob pena de ter a própria identidade implacavelmente fraturada.

O protocolo parece salvaguardar o profissional bombeiro da terrível experiência de desamparo diante de situações marcadas por grandes perdas patrimoniais e, principalmente, de vidas humanas. Essa prescrição, por vezes, mostra-se insuficiente, de onde surge um tensionamento entre não se deixar afetar e, paradoxalmente, precisar se colocar como sujeito para poder, criativamente, solucionar os impasses da realidade. É por meio de recursos subjetivos próprios que o bombeiro faz frente ao real que se lhe impõe, a despeito de qualquer prescrição. Nessa acepção, entende-se que quem salva é o sujeito, por meio de um tra- 
balho vivo sustentado na singularidade. Quanto mais flexíveis e plásticas as defesas empregadas, maiores as condições subjetivas de trabalhar - criativamente - sem adoecer.

O apoio da instituição ao sujeito que salva é vislumbrado como alternativa às defesas enrijecidas que fragilizam o psiquismo do profissional. $\mathrm{O}$ reconhecimento ofertado pela instituição aos seus dar-se-ia, de acordo com essa compreensão, em termos de legitimação do sofrimento vivido e da consideração deste como pertencente ao humano que trabalha. Trata-se de uma significativa mudança de perspectiva: da armadura do cavalheiro ao cavalheiro da armadura. A identidade do bombeiro está sustentada na existência do grupo. No grupo reside, também, a base de reconhecimento do sofrimento subjetivo e a possibilidade de fomento de defesas eficientes, mais flexíveis e menos onerosas aos sujeitos. À instituição Corpo de Bombeiros, dirige-se, portanto, a convocatória para oferta de espaços que permitam aos seus integrantes a sustentação da valorosa identidade de grupo, sem com isso perder de vista as particularidades e os impasses enfrentados por cada um de seus membros.

\section{Referências}

Bardin, L. (1977). Análise de conteúdo. Lisboa: 70.

Bleichmar, S. (2010). Psicoanálisis extramuros: Puesta a prueba frente a lo traumático. Buenos Aires: Entreideas.

Dejours, C. (1996). Uma nova visão do sofrimento humano nas organizações. In: O. Torres (Org.), O indivíduo na organização: Dimensões esquecidas (pp. 149-173). São Paulo, SP: Atlas.

Dejours, C. (2011). Addendum: Da psicopatologia à psicodinâmica do trabalho. In: S. Lancman, \& L. Sznelwar (Orgs.), Christophe Dejours: Da psicopatologia à psicodinâmica do trabalho (pp. 57-124). Brasília, DF: Paralelo 15.

Dejours, C. (2012b). Trabalho vivo tomo I: Sexualidade e trabalho. Brasília, DF: Paralelo 15.

Dejours, C. (2012a). Trabalho vivo tomo II: Trabalho e emancipação. Brasília, DF: Paralelo 15.

Figueiredo, L. C., \& Coelho Junior, N. (2008). Ética e técnica em psicanálise. São Paulo, SP: Escuta.

Freud, S. (2004). À guisa de introdução ao narcisismo. In: L. A. Hanns (Ed.), Escritos sobre a psicologia do inconsciente (Vol. 1, pp. 95-131). Rio de Janeiro, RJ: Imago. (Trabalho original publicado em 1914).

Freud, S. (2006). Além do princípio do prazer. In: L. A. Hanns (Ed.), Escritos sobre a psicologia do inconsciente (Vol. 2, pp. 123-198). Rio de Janeiro, RJ: Imago. (Trabalho original publicado em 1920).

Freud, S. (2006). Introdução à psicanálise das neuroses de guerra. In: J. Strachey (Ed.), Edição standard brasileira das obras psicológicas completas de Sigmund Freud (Vol. 17, pp. 221-231). Rio de Janeiro, RJ: Imago. (Trabalho original publicado em 1919).

Gonzales, R. M. B., Donaduzzi, J. C., Beck, C. L. C., \& Stekel, L. M. C. (2006). O estado de alerta: Um estudo exploratório com o corpo de bombeiros. Escola Anna Nery, 10(3), 370-377. https://doi.org/10.1590/S1414-81452006000300003

Hornstein, L. (2009a). Al yo le pasa de todo. In: H. Lerner, \& S. Sternbach (Orgs.), Organizaciones fronterizas: Fronteras del psicoanálisis (pp. 157-167). Buenos Aires: Lugar.

Hornstein, L. (2009b). Narcisismo: Autoestima, identidade, alteridade. São Paulo, SP: Via Lettera.

Kaës, R. (1991). Realidade psíquica e sofrimento nas instituições. In: R. Kaës, J. Bleger, E. Enriquez, F. Fornari, P. Fustier, R. Roussillon et al. (Orgs.), A instituição e as instituições: Estudos psicanalíticos (pp. 19-58). São Paulo, SP: Casa do Psicólogo.

Lancman, S. (2011). Apresentação: O mundo do trabalho e a psicodinâmica do trabalho. In: S. Lancman, \& L. Sznelwar (Orgs.), Christophe Dejours: Da psicopatologia à psicodinâmica do trabalho (pp. 31-43). Brasília, DF: Paralelo 15.

Lancman, S., \& Uchida, S. (2003). Trabalho e subjetividade: O olhar da psicodinâmica do trabalho. Cadernos de Psicologia Social do Trabalho, 6, 79-90. https://doi.org/10.11606/issn.1981-0490.v6i0p79-90

Monteiro, J. K., Maus, D., Machado, F. R., Pesenti, C., Bottega, D., \& Carniel, L. B. (2007). Bombeiros: Um olhar sobre a qualidade de vida no trabalho. Psicologia Ciência e Profissão, 27(3), 554-565. https://doi.org/10.1590/ S1414-98932007000300014 
Moraes, R. (1999). Análise de conteúdo. Educação, 22(37), 7-32.

Natividade, M. R. (2009). Vidas em risco: A identidade profissional dos bombeiros militares. Psicologia \& Sociedade, 21(3), 411-420. https://doi.org/10.1590/S0102-71822009000300015

Perrone, C., \& Moraes, E. G. (2014). Do trauma ao testemunho: Caminho possível de subjetivação. In: Sigmund Freud Associação Psicanalítica - SIG (Org.), Clínicas do testemunho: Reparação psíquica e construção de memórias (pp. 31-46). Porto Alegre, RS: Criação Humana.

Schenquerman, C. (2010). Prólogo. In: S. Bleichmar, Psicoanálisis extramuros: Puesta a prueba frente a lo traumático (pp. 9-14). Buenos Aires: Entreideas.

Sznelwar, L., \& Lancman, S. (2011). Nota dos organizadores para a primeira edição. In: S. Lancman, \& L. Sznelwar (Orgs.), Christophe Dejours: Da psicopatologia à psicodinâmica do trabalho (pp. 19-21). Brasília, DF: Paralelo 15.

Uchitel, M. (2011). Neurose traumática: Uma revisão crítica do conceito de trauma. São Paulo, SP: Casa do Psicólogo.

\section{Cristiano Dal Forno}

Professor Adjunto do Curso de Psicologia da Pontifícia Universidade Católica do Rio Grande do Sul (PUCRS). Psicólogo, Mestre e Doutor em Psicologia pela PUCRS. Rio Grande do Sul - RS. Brasil.

E-mail: cristiano.forno@pucrs.br

(iD) https://orcid.org/0000-0002-5299-7485

\section{Mônica Medeiros Kother Macedo}

Professora do Programa de Pós-Graduação em Psicanálise: Clínica e Cultura da Universidade Federal do Rio Grande do Sul (UFRGS). Psicóloga. Psicanalista. Doutora em Psicologia pela Pontifícia Universidade Católica do Rio Grande do Sul. Rio Grande do Sul - RS. Brasil. Bolsista Produtividade CNPq.

E-mail: monicakothermacedo@gmail.com

(iD) http://orcid.org/0000-0001-9347-8537

Recebido 21/08/2017

Aceito 07/05/2018

Received $08 / 21 / 2017$

Approved 05/07/2018

Recibido 21/08/2017

Aceptado 07/05/2018

Como citar: Dal Forno, C. e Macedo, M. K. (2019). Do Protocolo aos Desafios Cotidianos: a Experiência Profissional de Bombeiros Militares. Psicologia: Ciência e Profissão, 39, 1-15. https://doi.org/10.1590/1982-3703003184306

How to cite: Dal Forno, C. e Macedo, M. K. (2019). From Protocol to Daily Challenges: The Military Firefighter's Professional Experience. Psicologia: Ciência e Profissão, 39, 1-15.hhttps://doi.org/10.1590/1982-3703003184306

Cómo citar: Dal Forno, C. e Macedo, M. K. (2019). Del Protocolo a los Desafíos Cotidianos: la Experiencia Profesional de Bomberos Militares. Psicologia: Ciência e Profissão, 39, 1-15.https://doi.org/10.1590/1982-3703003184306 